\title{
DJ-1, a Target Protein for an Endocrine Disrupter, Participates in the Fertilization in Mice
}

\author{
Masahiko OKada, ${ }^{a}$ Ken-ichi Matsumoto, ${ }^{a, c}$ Takeshi Niki, ${ }^{c}$ Takahiro TAIRA, ${ }^{a, c}$ \\ Sanae M. M. IguchI-ArigA, ${ }^{b, c}$ and Hiroyoshi ArIGA ${ }^{*, a, c}$ \\ ${ }^{a}$ Graduate School of Pharmaceutical Sciences, Hokkaido University; ${ }^{b}$ College of Medical Technology, Hokkaido \\ University; Kita-ku, Sapporo 060-0812, Japan: and ${ }^{C}$ CREST, Japan Science and Technology Corporation; 4-1-8 Honcho, \\ Kawaguchi, Saitama 332-0012, Japan. Received March 6; 2002; accepted March 19, 2002
}

DJ-1 was first identified as an activated ras-dependent oncogene product and was later also found to be an infertility-related protein affected by sperm toxicants such as ornidazole (OR) and epichlorohydrin. These findings suggest that DJ-1 has functions in both somatic cells and sperm. In this study, to determine the relationship between DJ-1 and an endocrine disrupter and to determine the functions of DJ-1 in sperm, in vitro fertilization experiments were carried out using eggs and sperm extracted from mice that had or had not been treated with OR. We found that the amount of DJ-1 in sperm and the efficiency of fertilization decreased with the increasing dose of OR to which the mice were exposed. The addition of an anti-mouse DJ-1 serum to sperm solution before the in vitro fertilization reaction with eggs resulted in a decrease in the efficiency of fertilization to about onethird of that when pre-immune serum was added to sperm solution, indicating that DJ-1 participates in the fertilization.

Key words DJ-1; fertilization; endocrine disrupter

DJ-1 was first identified by our group as a novel candidate of the oncogene product that transformed mouse NIH3T3 cells in cooperation with activated ras. ${ }^{1}$ The human DJ-1 gene is mapped at chromosome 1p36.2-p36.3, where a hot spot of chromosome abnormalities has been reported in several tumors. ${ }^{2)}$ However, the mechanism by which cells are transformed has not been determined. DJ-1 was also identified as a regulatory component of an RNA-binding protein complex, RS . ${ }^{3)}$ Furthermore, CAP-1 or SP22, a rat homologue of human DJ-1, has been identified as a key protein related to infertility of male rats that were exposed to sperm toxicants such as ornidazole and epichlorohydrin. DJ-1 in the sperm and epididymis decreased in parallel with the subsequent infertility of the rats. ${ }^{4-7)}$ It has been shown that DJ-1 is expressed preferentially in the testis and moderately in other tissues. DJ-1 is also expressed in the sperm head and is translocated to the cytoplasmic side of sperm after sperm toxicant treatment in infertile rats. ${ }^{7-9)}$ DJ-1 is therefore thought to play roles in both somatic cells and sperm.

We have shown that DJ-1 acts as a positive regulator for a suppressed state of the androgen receptor (AR) by sequestering PIASx $\alpha$, a member of the PIAS family of proteins that functions as a negative regulator for the AR by preventing AR DNA-binding activity in monkey CV-1, monkey CosI and mouse TM4 cells, a cell line of sertoli cells. ${ }^{10)}$ When the AR was activated by PIASx $\alpha$ which also acts as a positive regulator for the AR in human HepG2 cells, a hepatoma cell line, it was found that DJ-1 no longer had an effect on the activity of the activated AR. ${ }^{10)}$ These results suggest that DJ-1 affects the production of sperm by activating the AR to express male-specific genes.

Furthermore, it has recently been reported that DJ-1 was expressed and that its pI was changed from pI6.2 to pI5.8 by treatment of cells with paraquat and endotoxin, which induce reactive oxygen species. ${ }^{11,12)}$ It has also been shown that DJ-1 is a circulating tumor antigen in breast cancer, in which DJ-1 is secreted from cells to serum. ${ }^{13)}$ These results suggest that DJ-1 works in the defense process against several stresses in somatic cells.

In this study, we found that the amount of DJ-1 in sperm and fertilization activity decreased in mice treated with orinidazole. We also found that an anti-DJ-1 antiserum inhibited the fertilization activity, suggesting that DJ-1 plays a direct role in fertilization in mice.

\section{MATERIALS AND METHODS}

Administration of Ornidazole to Mice ICR male mice at 8 weeks of age were orally administered various doses of ornidazole (OR), which was dissolved in $0.2 \%$ CM-cellulose and $1-2$ drops of Tween 20 , by a $1-\mathrm{ml}$ syringe attached in an oral sonde.

In Vitro Fertilization Assay ICR female mice at 4 weeks of age were injected intraperitoneally with $5 \mathrm{IU}$ of pregnant mare serum gonadotropin (PMS). At $48 \mathrm{~h}$ after the PMS injection, the mice were again injected intraperitoneally with $5 \mathrm{IU}$ human chorionic gonadotropin (hCG). At $14 \mathrm{~h}$ after the second injection, the eggs were extracted from the fallopian tubes of female mice that had been injected and were cultured in vitro in a $35-\mathrm{mm}$ dish in M16 medium. At the same time as the extraction of eggs, sperm was extracted from the cauda epididymis of male mice and cultured in vitro in a 24-well dish in M16 medium after the sperm number had been adjusted to $1-2 \times 10^{5} / \mathrm{ml}$ of M16 medium. Ninety min after incubation, a one-tenth volume of sperm solution containing $1-2 \times 10^{5}$ sperm was added to the culture medium of eggs and cultured for $36 \mathrm{~h}$. Fertilized eggs were defined as cleaved eggs in culture, and their numbers were counted under a microscope.

Establishment of DJ-1-Transgenic Mice Establishment of DJ-1-transgenic mice was carried out in Nippon SLC Ltd. Briefly, ICR mice were injected with an SmaI fragment containing EF promoter-conjugated human DJ-1-HA derived from $\mathrm{pEF}-\mathrm{DJ}-1-\mathrm{HA}{ }^{1,10)}$ After mating with F1 mice harboring the EF promoter-DJ-1-HA fragment, F2 mice harboring the DJ-1-HA fragment homozygously were obtained and used 
for the experiments.

Detection of DJ-1 in Mice Sperm The cauda epididymis of each male mouse was exposed and sperm was extracted with a syringe and transferred to a tube containing $5 \%$ Ficoll in $\operatorname{PBS}(-)$. The sperm solution was centrifuged at $14000 \mathrm{rpm}$ for $5 \mathrm{~min}$, and the supernatant fraction was stored. The pellet fraction was then suspended in RIPA buffer, sonicated, and centrifuged at $14000 \mathrm{rpm}$ for $5 \mathrm{~min}$, and the supernatant fraction was stored. The proteins in the first and second supernatant fractions were analyzed by Western blotting using an anti-ME1 antibody $^{14)}$ to examine the contamination of epididymis proteins and used for the fertilization experiments. This anti-mouse DJ-1 antibody was prepared after immunization of GST-mouse DJ-1 expressed in and purified from $E$. coli to rabbits, followed by the absorption of serum with the purified GST, and used for detection of DJ-1 in the second supernatant fraction by Western blotting.

\section{RESULTS AND DISCUSSION}

Effect of Ornidazole on Expression of DJ-1 and Fertilization Activity in Mice Three to five ICR mice at 8 weeks of age were orally administered 2 or $4 \mathrm{mmol} / \mathrm{kg} / \mathrm{d}$ of ornidazole (OR) dissolved in CM-cellulose for $14 \mathrm{~d}$, and mice were also orally administered CM-cellulose alone as controls. These doses of OR were found not to be toxic to mice, and neither the whole body nor testes weight changed significantly (data not shown). Proteins were then extracted from testes and sperm, which was squeezed from the cauda epididymis, and blotted with an anti-mouse DJ-1 antibody. The result showed that the amount of DJ-1 did not change significantly in testes (data not shown) but decreased significantly in sperm in a dose-dependent manner; weak signals of DJ-1 bands appeared in mice that had been exposed to $2 \mathrm{mmol} / \mathrm{kg} / \mathrm{d}$ but no signals appeared in mice that had been exposed to $4 \mathrm{mmol} / \mathrm{kg} / \mathrm{d}$ (Figs. 1A, 1B, respectively), indicating that as in rats, OR affects the amount of DJ-1 in mice sperm.

An in vitro fertilization experiment was carried out to determine the effect of OR on fertilization. Female mice were treated with PMS and hCG to induce superovulation, and eggs were extracted from the fallopian tubes. Sperm was extracted from the cauda epididymis of male mice that had been orally administered $4 \mathrm{mmol} / \mathrm{kg} / \mathrm{d}$ of OR for $14 \mathrm{~d}$ and cultured with the extracted eggs for $36 \mathrm{~h}$, during which time the second polar body appeared and then the eggs began to cleave. Fertilization efficiency was determined as a percent of the fertilized eggs/total eggs used. The results of in vitro fertilization showed that treatment of male mice with OR caused a reduction in the efficiency of fertilization to less than half of that without OR treatment $(11.3 \%$ with OR treatment vs. $24.6 \%$ without OR treatment) (Table 1). These results indicate that there is a parallel relationship between the amount of DJ-1 in sperm and fertilization activity in mice.

Effect of an Anti-DJ-1 Antiserum on the Fertilization Activity of Mice To further examine the role of the activity of DJ-1 in the fertilization process, the anti-mouse DJ-1 antiserum or preimmune serum was added to sperm solution before the in vitro fertilization reaction with eggs, and the fertilization efficiency was determined as described above (Table 2). In 5 experiments, $37.8 \%$ of the eggs on average

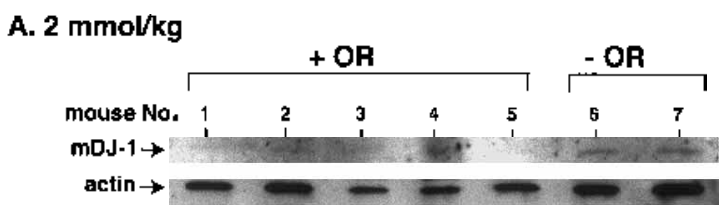

B. $4 \mathrm{mmol} / \mathrm{kg}$

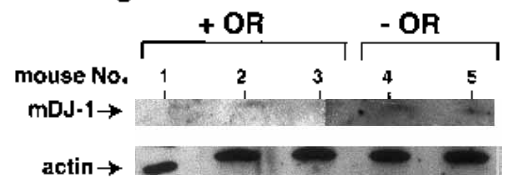

OR: arnidazole

Fig. 1. Effect of Ornidazole Treatment on DJ-1 Expression in Mouse Sperm

ICR male mice at 8 weeks of age were orally administered 2 or $4 \mathrm{mmol} / \mathrm{kg} / \mathrm{d}$ of ornidazole (OR) for $14 \mathrm{~d}$, and control mice were similarly treated with a buffer. Then proteins were extracted from sperm that had been squeezed from the cauda epididymis and blotted with an anti-mouse DJ-1 antibody or anti-actin antibody (C4, Chemicon).

Table 1. Effect of Ornidazole on the Fertilization Activity of Male Mice

\begin{tabular}{ccrrr}
\hline \hline & 1 & 2 & 3 & Total \\
\hline- OR & $6 / 18$ & $2 / 13$ & $6 / 26$ & $14 / 57$ \\
$\%$ & 33.3 & 15.4 & 23.1 & 24.6 \\
+ OR & $5 / 24$ & $1 / 15$ & $0 / 14$ & $6 / 53$ \\
$\%$ & 20.8 & 6.7 & 0.0 & 11.3 \\
\hline
\end{tabular}

ICR male mice at 8 weeks of age were orally administered $4 \mathrm{mmol} / \mathrm{kg} / \mathrm{d}$ of OR for $14 \mathrm{~d}$, and sperm from the male mice was cultured with the extracted eggs for $36 \mathrm{~h}$. Fertilized eggs were counted under a microscope. Fertilization efficiency is expressed as number of fertilized eggs/number of total eggs used in the experiment.

Table 2. Effect of an Anti-DJ-1 Antiserum on the Fertilization Activity of Male Mice

\begin{tabular}{lrrrcrr}
\hline \hline & 1 & \multicolumn{1}{c}{2} & \multicolumn{1}{c}{4} & 4 & 5 & Total \\
\hline No serum & $12 / 19$ & $4 / 7$ & $2 / 10$ & $5 / 22$ & $8 / 24$ & $31 / 82$ \\
$\%$ & 63.2 & 57.1 & 20.0 & 22.7 & 33.3 & 37.8 \\
Preimmune & $1 / 2$ & $1 / 2$ & $21 / 35$ & $3 / 34$ & $22 / 37$ & $48 / 110$ \\
$\%$ & 50.0 & 50.0 & 60.0 & 8.8 & 59.5 & 43.6 \\
Anti-DJ-1 serum & $1 / 15$ & $0 / 9$ & $1 / 29$ & $7 / 20$ & $9 / 22$ & $18 / 102$ \\
$\%$ & 6.7 & 0.0 & 3.4 & 35.0 & 31.0 & 17.6
\end{tabular}

Solutions of sperm extracted from the cauda epididymis of the male mice were incubated with a ten fold dilution of an anti-mouse DJ-1 antiserum or preimmune serum at $37^{\circ} \mathrm{C}$ for $90 \mathrm{~min}$ and then cultured with the extracted eggs for $36 \mathrm{~h}$. Fertilized eggs were counted under a microscope. Fertilization efficiency is expressed as number of fertilized eggs/number of total eggs used in the experiment.

were fertilized without serum treatment. While treatment with preimmune serum resulted in a slight increase in the efficiency of fertilization of eggs to $43.6 \%$, treatment of sperm with the anti-mouse DJ-1 antiserum resulted in a reduction in efficiency to $17.6 \%$. Furthermore, it was observed under a microscope that sperm was not able to bind to the egg surface after treatment of the sperm with the anti-DJ-1 antiserum. These results indicate that DJ-1 directly participates in the fertilization reaction.

Establishment of Transgenic Mice Expressing Human DJ-1 Transgenic mice expressing human DJ-1 were established by injection of a fragment containing the cDNA of human HA-tagged DJ-1 linked with the promoter for the elongation factor-a (EF) gene into ICR mice eggs. After mat- 


\section{A. Southern blot}

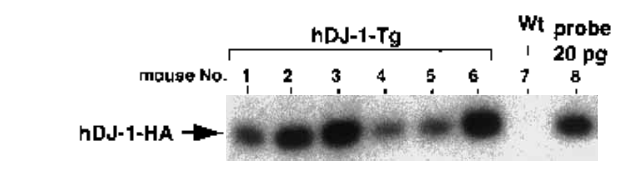

B. Western blot

(1) tissue

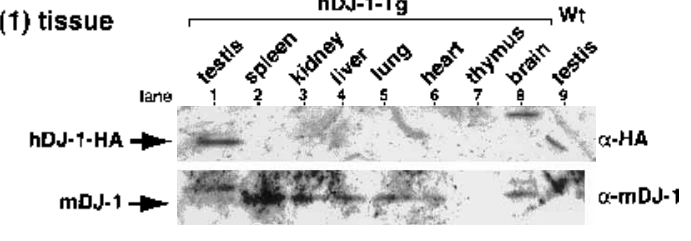

(2) sperm

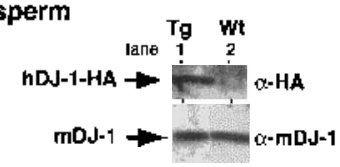

Fig. 2. Establishment of DJ-1 Transgenic Mice and Expression of DJ-1

ICR mice were injected with a fragment containing HA-tagged human DJ-1 cDNA linked with EF promoter. (A) Southern blot analysis was carried out to examine the presence of the transgene in mice, and an example of the results is shown. Total DNAs were extracted from mouse tails by the conventional procedure or using a mouse tail extraction kit (Gentra Systems), digested with EcoRI and BamHI, transferred to a nitrocellulose membrane, and hybridized with a 32P-labeled EcoRI-BamHI fragment of pEF-DJ-1-HA. ${ }^{1,10)}$ Mouse numbers $1-6$ indicate the mice harboring the transgene, and No. 7 indicates a mouse without the transgene. (B) Total proteins were extracted from several kinds of tissues (1) or sperm (2) from DJ-1-transgenic mouse (lanes (1)-1-8) or a normal mouse (lane (1)-9) and blotted with an anti-HA monoclonal antibody (upper part) or an anti-mouse DJ-1 polyclonal antibody (lower part). Only the results for the testis are shown in the case of the normal mouse (lane 9).

ing between F1 male and female mice that harbor the transgene in a heterogous gene, a line of F2 mice harboring it in homozygous genes was established. Examples of mice harboring the transgene as detected by Southern blotting are shown in Fig. 2A. In these examples, an average of $10-20$ copies/haploid genome of the transgene were integrated into the mice genome. The expression of DJ-1 in a transgenic mouse was then examined by Western blotting and the results are shown in Fig. 2B. Human DJ-1-HA was found to be preferentially expressed in the testis, while the endogenous mouse DJ-1 was expressed ubiquitously in all of the tissues examined. Since we and others have shown that DJ-1 is strongly expressed in the testis and moderately in other tissues, ${ }^{4-8)}$ it is thought that human DJ-1 exogenously added to mice reduced the expression level of the endogenous mouse dj-1 gene. In sperm, on the other hand, while almost equal amounts of the mouse DJ-1 were expressed in the transgenic and normal mice, only exogenous human DJ-1-HA was expressed in the transgenic mouse (Fig. 3C). An in vitro fertilization reaction was then carried out using eggs from a normal female mouse and sperm from a DJ-1 transgenic mouse (Table 3). Although a marginal increase in fertilization efficiency was observed in the reaction using sperm from the DJ-1-transgenic mouse, the difference was not significant. These results suggest that although the DJ-1-transgenic mouse showed a higher expression level of DJ-1 in sperm than that in the normal mouse, the amount of endogenous DJ-1 is sufficient for the mouse to succeed in fertilization.

In this paper, we first described the effect of OR, an antimale toxicant, on the expression of DJ-1 in sperm and on the fertilization activity in vitro of male mice treated with this
Table 3. Fertilization Activity of Sperm from DJ-1 Transgenic Mice

\begin{tabular}{crrrrrr}
\hline \hline & 1 & 2 & 3 & \multicolumn{1}{c}{4} & 5 & Total \\
\hline Normal & $10 / 32$ & $8 / 27$ & $2 / 19$ & $30 / 72$ & $6 / 18$ & $56 / 168$ \\
$\%$ & 31.3 & 29.6 & 10.5 & 41.7 & 33.3 & 33.3 \\
$\mathrm{Tg}$ & $12 / 42$ & $27 / 37$ & $2 / 24$ & $32 / 74$ & $6 / 22$ & $79 / 199$ \\
$\%$ & 28.6 & 73.0 & 8.3 & 43.2 & 27.3 & 39.7 \\
\hline
\end{tabular}

Solutions of sperm extracted from the cauda epididymis of DJ-1 transgenic male mice or normal mice were cultured with extracted eggs for $36 \mathrm{~h}$. Fertilized eggs were counted under a microscope. Fertilization efficiency is expressed as number of fertilized eggs/number of total eggs used in the experiment.

drug. As was reported for rats, ${ }^{5)}$ OR was found to reduce the level of DJ-1 expression, thereby leading to low fertilization activity of sperm. Then it was found that an anti-DJ-1 antiserum but not preimmune serum abrogates the binding to the egg and the fertilization activity of sperm, indicating that DJ1 directly participates in the fertilization reaction. Although the results presented here were obtained using the ICR strain of mice, we also obtained similar results using the B6 strain of mice, suggesting that DJ-1 plays a role in fertilization in both these strains. During preparation of this manuscript, Klinefelter et al. ${ }^{15)}$ reported results of experiments using rats that were similar to those obtained in this study using mice. They showed that an anti-SP22/DJ-1 antiserum abrogated the fertilization activity of sperm from rats and also that this inhibitory effect of the anti-SP22 antiserum decreased when zona-free eggs were used instead of intact eggs, suggesting that SP22/DJ-1 works to enable binding of sperm to the egg surface and then penetration of the egg surface. ${ }^{15)}$ Since DJ-1 possesses an amino acid sequence that is homologous to that of enzymes such as protease $i$ or catalase, DJ-1 might have an intrinsic enzyme activity that is necessary for the fertilization activity of sperm as described above. We are now testing this possibility.

We have established DJ-1-transgenic mice in which human DJ-1 was preferentially expressed in the testis even when the latter was driven under the elongation factor a gene promoter. This suggests that DJ-1 itself contains the motif or associates with other proteins that are necessary for localization in testis. Since the number of sperm is sufficient for successful fertilization in the normal mouse, the fertilization efficiency of sperm from the DJ-1 transgenic mouse was found to be similar to that of the normal mouse. DJ-1 transgenic mice, however, will be useful to analyze functions of DJ-1.

Acknowledgments We thank Yoko Misawa and Kiyomi Takaya for their technical assistance. This work was supported by a grant from the Ministry of Education, Science, Sports, Culture and Technology of Japan.

\section{REFERENCES}

1) Nagakubo D., Taira T., Kitaura H., Ikeda M., Tamai K., Iguchi-Ariga S. M. M., Ariga H., Biochem. Biophys. Res. Commun., 231, 509-513 (1997).

2) Taira T., Takahashi K., Kitagawa R., Iguchi-Ariga S. M. M., Ariga H., Gene, 263, 285-292 (2001).

3) Hod Y., Pentyala S. N., Whyard T. C., El-Maghrabi M. R., J. Cell. Biochem., 72, 435-444 (1999).

4) Klinefelter G. R., Laskey J. W., Ferrell J., Suarez J. D., Roberts N. L., J. Androl., 18, 139-150 (1997).

5) Wagenfeld A., Yeung C. H., Strupat K. K., Cooper T. G., Biol. 
Reprod., 58, 1257-1265 (1998).

6) Wagenfeld A., Gromoll J., Cooper T. G., Biochem. Biophys. Res. Commun., 251, 545-549 (1998).

7) Welch J. E., Barbee R. R., Roberts N. L., Suarez J. D., Klinefelter G. R., J. Androl., 19, 385-393 (1998).

8) Wagenfeld A., Yeung C. H., Shivaji S., Sundareswaran V. R., Ariga H., Cooper T. G., J. Androl., 21, 954-963 (2000).

9) Whyard T. C., Cheung W., Sheynkin Y., Waltzer W. C., Hod Y., Mol. Reprod. Dev., 55, 189-196 (2000).

10) Takahashi K., Taira T., Niki T., Seino C., Iguchi-Ariga S. M. M., Ariga H., J. Biol. Chem., 276, 37556-37563 (2001).
11) Mitsumoto A., Nakagawa, Y., Takeuchi A., Okawa K., Iwamatsu A., Takanezawa Y., Free Radic. Res., 35, 301-310 (2001).

12) Mitsumoto A., Nakagawa Y., Free Radic Res., 35, 885-893 (2001).

13) Le Naour F., Misek D. E., Krause M. C., Deneux L., Giordano T. J., Scholl S., Hanash S. M., Clinical Cancer Res., 7, 3328-3335 (2001).

14) Nakamura Y., Takayama N., Minamitani T., Ikuta T., Ariga H., Matsumoto K., Gene, 251, 55-62 (2000).

15) Klinefelter G. R., Welch J. E., Perreault S. D., Moore H. D., Zucker R. M., Suarez J. D., Roberts N. L., Bobseine K., Jeffay S., J. Androl., 23, $48-63$ (2002). 